\title{
ULTRASOUND-GUIDED ERECTOR SPINAE PLANE BLOCK AS A POSTOPERATIVE ANALGESIA TECHNIQUE FOR THORACOSCOPY WITH TALC PLEURODESIS
}

R. Inácio ${ }^{1}$, A. Delgado ${ }^{1}$.

${ }^{1}$ Hospital Prof. Dr. Fernando da Fonseca E.P.E,

Department of Anesthesiology and Pain Medicine, Amadora, Portugal.

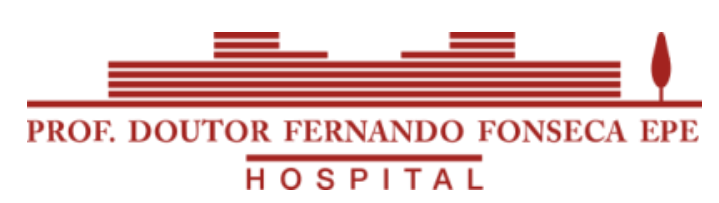

\section{Background and Aims}

The erector spinae plane (ESP) block is a newly described and effective interfascial plane block for thoracic and abdominal surgery.

It involves injection of local anesthetic between erector spinae muscles group and thoracic transverse processes. The site of injection is distant from the pleura, major blood vessels, and spinal cord. Therefore, compared to other techniques used for thoracic analgesia, as thoracic epidural, thoracic paravertebral, and intercostal blocks, ESP block is a much safer block with relatively few contraindications and easier to perform.

\section{Methods}

We present the case of a 64-year-old male patient, ASA 2, scheduled for thoracoscopy with talc pleurodesis due to recurrent primary spontaneous pneumothorax. The procedure was performed under general anesthesia and went uneventful. During PACU recovery the patient presented moderate to severe pain (NRS pain score 7/10).

We performed an ultrasound-guided ESP block at $\mathrm{T}_{5}$ level with $30 \mathrm{~mL}$ Ropivacaine $0.375 \%$ plus adrenaline $5 \mathrm{ug} / \mathrm{mL}$. The block was administered successfully with observation of the solution spread between transverse process and the erector spinae muscles.

\section{Results}

After 30 minutes patient NRS pain score was $1 / 10$ with no limitation of respiratory movements. Postoperative analgesia was complemented with paracetamol $1 \mathrm{~g}$ plus ketorolac $30 \mathrm{mg}$ tid. During the 48-hour hospital stay patient presented only mild pain (maximum NRS pain score of $2 / 10$ ). No opioids were used and the patient reported a very high level of satisfaction.

\section{Conclusions}

This relatively simple and safe block dramatically reduced the patient NRS pain score and IV pain medication needs, mainly opioids, optimizing respiratory function ant patient mobilization.

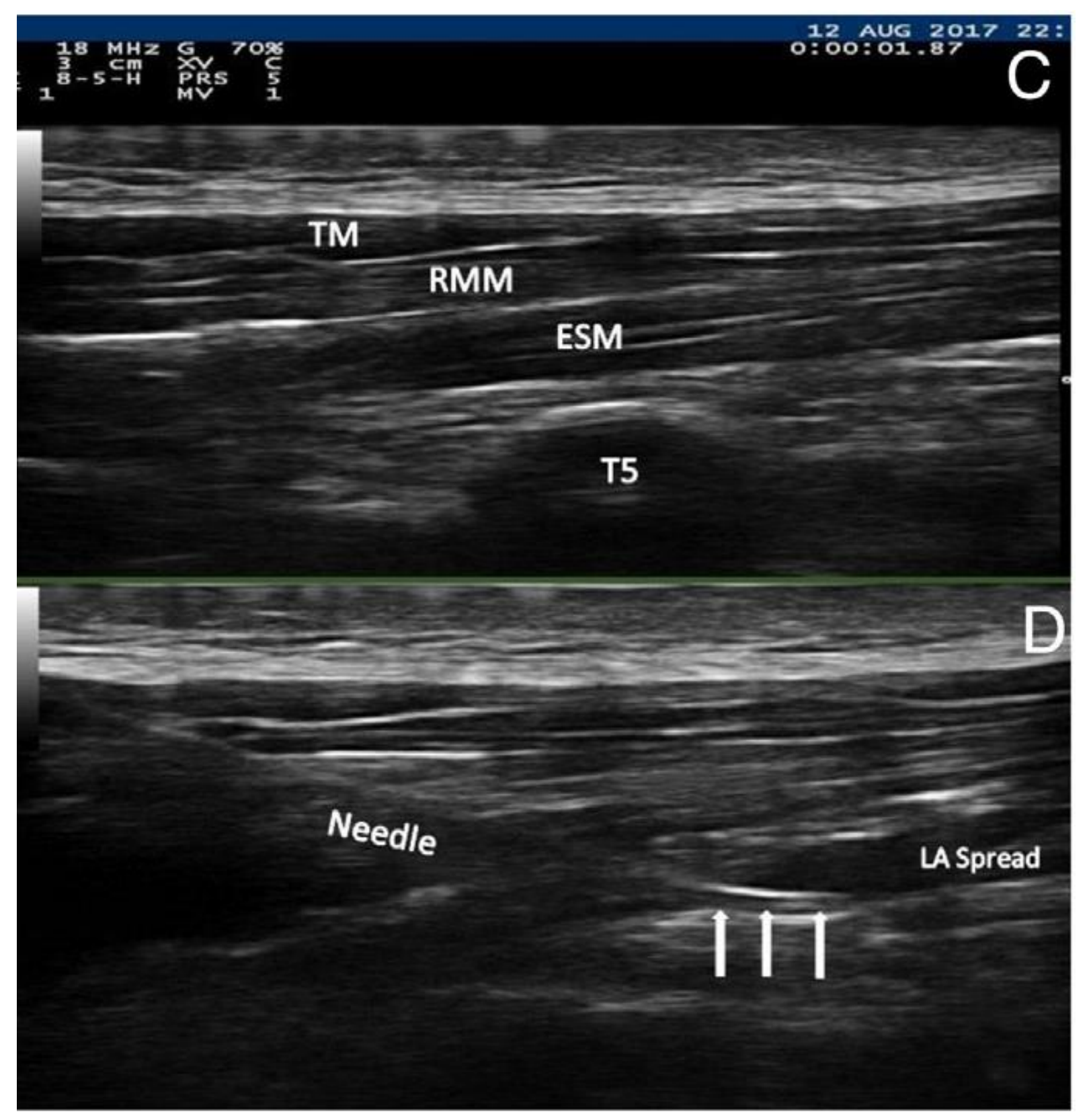

Image 1: Needle placement during PENG block

1. Yayika AM, Ahiskalioglu A, Çelik EC, Aya A, Ozenogluc A. Bloqueio do plano do eretor da espinha para analgesia pós-operatória de cirurgia de fratura de múltiplas costelas: relato de caso. Rev Bras Anestesiol. 2019;69(1):91-94

2. Forero M, Adhikary SD, Lopez H, et al. The erector spinae planeblock: a novel analgesic technique in thoracic neuropathic pain. Reg Anesth Pain Med. 2016;41:621-7 